\title{
Energias Renováveis e Sustentabilidade: um olhar geográfico para o parque eólico de Marcolândia, estado do Piaú, Brasil
}

\author{
Renewable energy and Sustainability: a geographic view to the wind power complex of \\ Marcolândia, state of Piauí, Brazil
}

CAMPÊLOํㅣ, J. C.; ALBUQUERQUE², E .L. S.

jaerlec@outlook.com

\begin{abstract}
Resumo
Em virtude da preocupação com os problemas ambientais, no que se refere à geração de energia, surgiram nas últimas décadas fontes alternativas conhecidas como energias renováveis, pautadas no desenvolvimento sustentável. Neste sentido, ao analisar as condições ambientais e socioeconômicas no município de Marcolândia, estado do Piauí, a partir da geração de energia eólica no Complexo Chapada do Piauí I, o estudo visa constatar a questão da sustentabilidade da geração deste tipo de energia, concomitante com a atividade econômica originalmente desenvolvida, e as medidas mitigadoras utilizadas a fim de minimizar os impactos socioambientais causados com a implantação e operação do mencionado empreendimento. $\mathrm{Na}$ perspectiva de contemplar a temática do trabalho, deve-se considerar o tripé: ambiental, social e econômico, tendo em vista as particularidades que se materializam no ambiente. Neste sentido, além da geração de energia, os proprietários agregam valores as suas terras e ganham rendimentos por meio da atividade agropecuária, consorciadas aos aerogeradores instalados.
\end{abstract}

Palavras-chave: Energia eólica. Chapada do Araripe. Agropecuária.

\begin{abstract}
Because of concern about environmental problems, with regard to power generation, have emerged in recent decades alternative sources known as renewable energy, grounded in sustainable development. In this sense, when analyzing the environmental and socioeconomic conditions in the municipality of Marcolândia, state of Piauí, from wind power generation in Piauí Chapada Complex I, the study aims to establish the issue of sustainability of the generation of this type of energy, concomitant with economic activity originally developed, and the mitigating measures used to minimize the environmental impacts caused by the implementation and operation of the said undertaking. With a view to contemplate the theme of the work, it must consider three pillars: environmental, social and economic, in view of the special features that materialize in the environment. In this sense, in addition to power generation, the owners add value their land and earn income through agricultural activity, the consortium installed wind turbines.
\end{abstract}

Keywords: Wind power . Chapada do Araripe. Agropecuary.

\section{INTRODUÇÃO}

Em virtude da preocupação com os problemas ambientais, no que se refere à geração de energia, surgiram nas últimas décadas fontes alternativas conhecidas como energias renováveis, pautadas no desenvolvimento sustentável e na perspectiva de suprir as necessidades energéticas buscadas pela sociedade.

A partir da década de 1980 foram iniciados, de forma mais efetiva, os debates sobre as questões ambientais, em que o conceito de Desenvolvimento Sustentável, introduzido e difundido a partir do Relatório Brundtland, propõe o desenvolvimento como "aquele que atende às necessidades do 
presente sem comprometer a possibilidade das gerações futuras atenderem às suas necessidades" (LOPEZ, 2012, p. 318).

De acordo com Simas e Pacca (2013), o citado Relatório deixa claro que o desenvolvimento sustentável está relacionado não só com a economia, mas também com o meio ambiente e com a sociedade, assim podendo ser aplicado com outras políticas sociais e colaborando com o desenvolvimento regional e local.

Ao considerar as formas como a sociedade apropria-se dos recursos naturais, com ênfase em suas necessidades energéticas, o quadro ambiental do planeta acaba se alterando, em conseqüência principalmente da utilização de combustíveis fósseis na geração de energia, tendendo ao aquecimento global e outros problemas ambientais derivados.

Nesta conjuntura, Sachs (2011) afirma que é necessária a substituição das energias fósseis, que são responsáveis por grandes impactos ambientais, pelo leque de energias renováveis, como a solar, a eólica e as bioenergias, pois estas são fontes limpas que não alteram o meio ambiente de forma significativa, quando comparadas aos combustíveis fósseis.

No que tange ao potencial eólico brasileiro, pode-se considerar que o Brasil é favorecido em ventos, pois se caracteriza por uma presença duas vezes maior que a média mundial e com uma variabilidade menor em toda a sua extensão, com destaque para a Região Nordeste (FADIGAS, 2011).

Neste sentido, ao analisar as condições ambientais e socioeconômicas no município de Marcolândia, estado do Piauí, a partir da geração de energia eólica no Complexo Eólico Chapada do Piauí I (Figura 01), que é o recorte espacial adotado na pesquisa, o presente estudo visa constatar a questão da sustentabilidade da geração deste tipo de energia, concomitante com a atividade econômica originalmente predominante, e as medidas mitigadoras utilizadas a fim de minimizar os impactos socioambientais causados com a implantação e operação do mencionado empreendimento.

Com relação à escolha do tema em foco, este se justifica, principalmente, pela iniciativa de analisar a questão da geração de energias renováveis, com enfoque na energia eólica, em virtude de ser uma temática atual relacionada à questão da sustentabilidade. Ao mesmo tempo, tem-se o município de Marcolândia-Pi (Figura 02), este localizado no semiárido piauiense, que durante décadas ficou à margem do desenvolvimento econômico no estado do Piauí. 


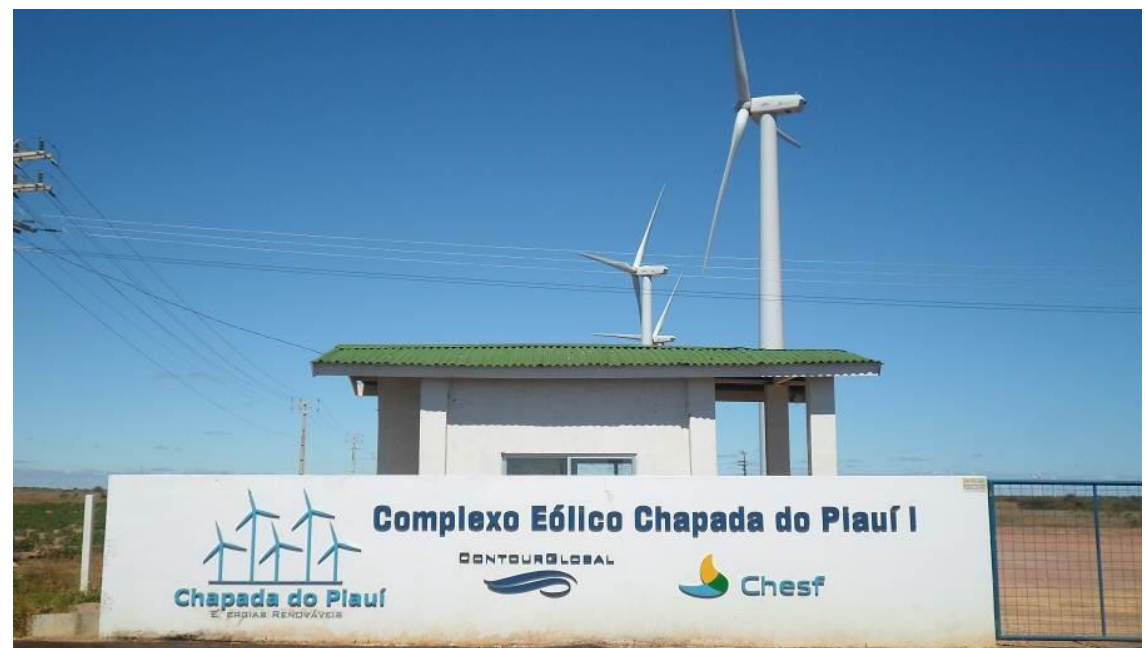

Figura 01 - Entrada do Complexo Eólico Chapada do Piauí I, Marcolândia-PI. Fonte: Campêlo (2016).

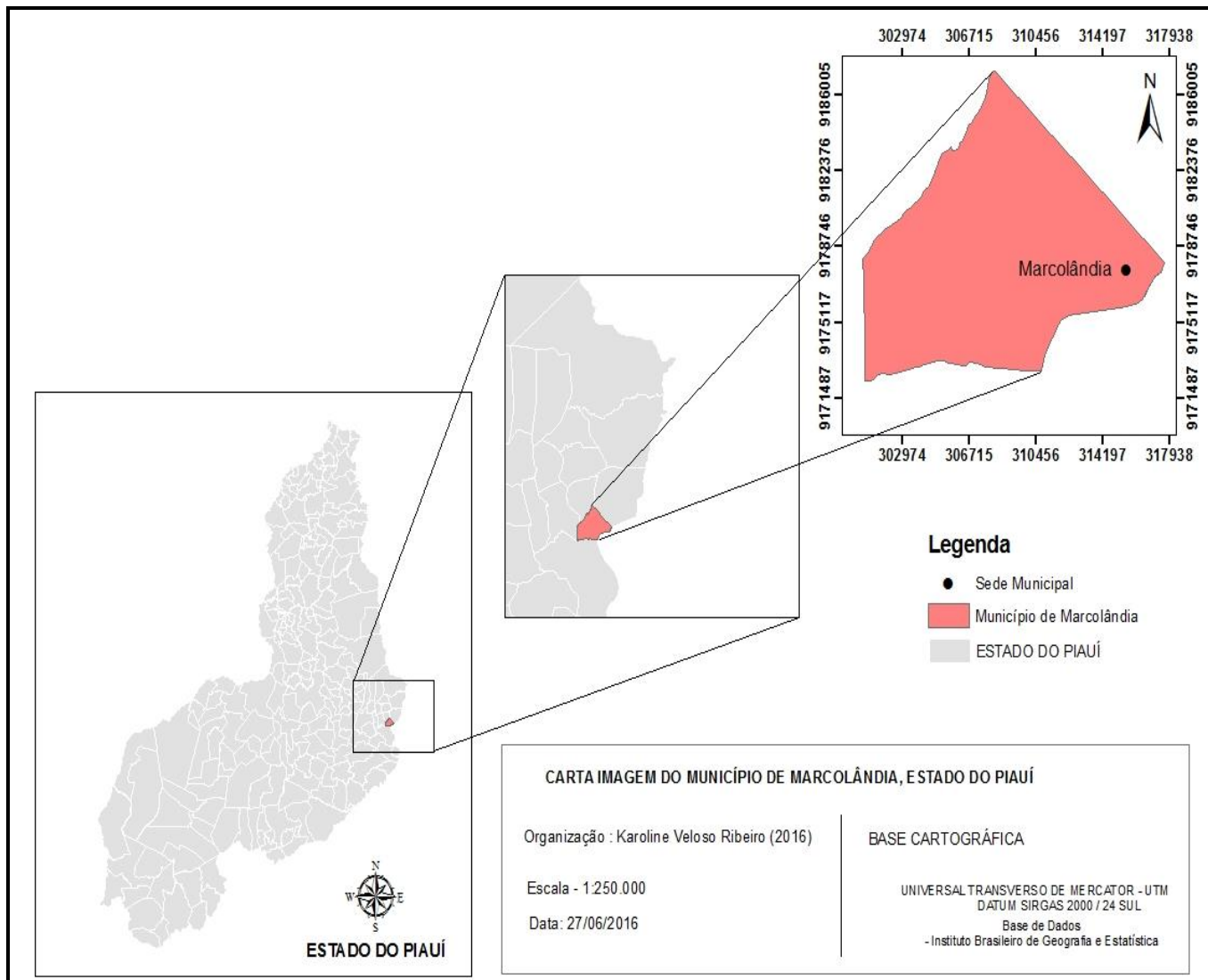

Figura 02 - Mapa de Localização do município de Marcolândia-PI. Organização: Campêlo (2016).

\section{METODOLOGIA}

Discutir a questão da sustentabilidade a partir da geração de energia eólica de um setor espacial compreende um grande esforço teórico-metodológico. Diante disso, através do estudo em epígrafe, buscou-se realizar uma pesquisa bibliográfica no que se refere especificamente à geração de energia 
eólica, considerando para isto livros, artigos, monografias, dissertações e teses, além de visitas a instituições e websites especializados.

É importante destacar que durante esta etapa houve tanto facilidade como dificuldade no levantamento de informações relevantes para o desenvolvimento do trabalho, seja durante a pesquisa de campo e ainda devido à linha de pesquisa dos autores que trabalham com os tópicos utilizados, em certos momentos, apresentar elevado número de publicações relevantes, como em outro caso o número de publicação ser escasso, já que é um tema abrangente.

Os procedimentos adotados e o conjunto metodológico para a realização do presente estudo foram agrupados no organograma abaixo (Figura 03).

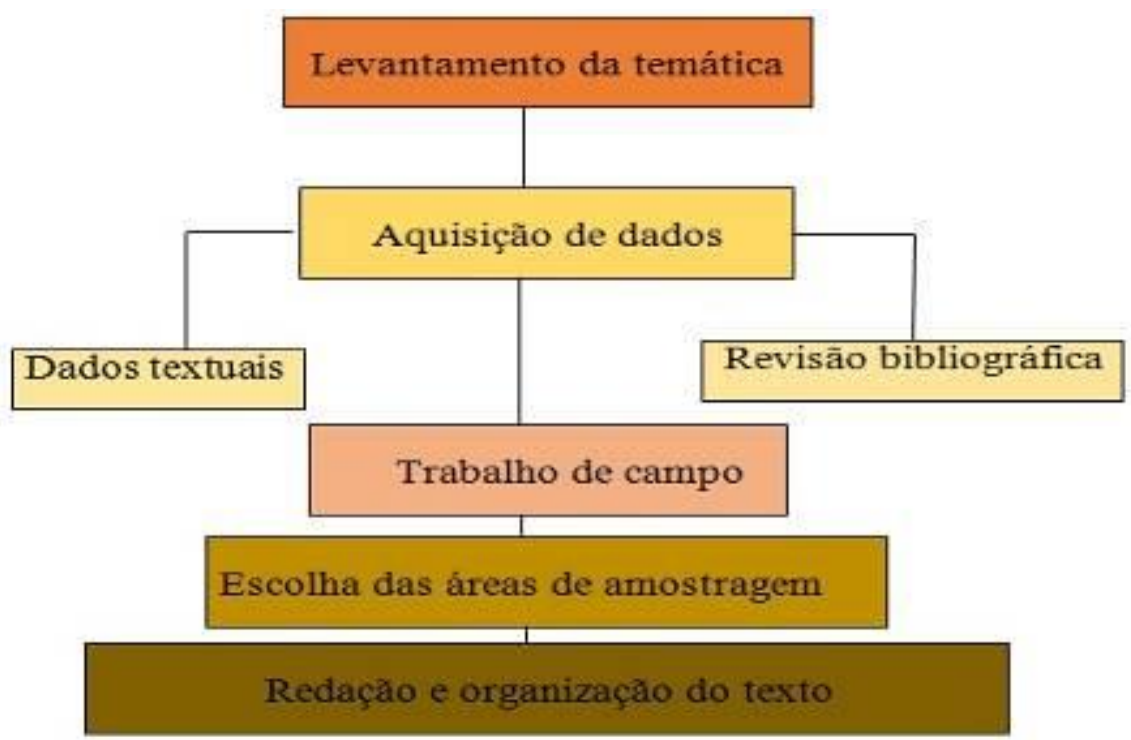

Figura 03 - Organograma com a sequência metodológica do trabalho. Fonte: Campêlo (2016).

\section{RESULTADOS E DISCUSSÃO}

Marcolândia é um município piauiense que dista aproximadamente $412 \mathrm{~km}$ da capital do Estado, Teresina. Possui área territorial de $140 \mathrm{~km}^{2}$, população de 7.812 habitantes e densidade demográfica de 54,30 hab./km² (IBGE, 2010). O município está inserido no Complexo Eólico Chapada do Piauí I (Figura 04). Conforme Piauí (2015), o complexo mencionado possui atualmente 115 aerogeradores instalados, sendo 7 em Padre Marcos, 22 em Simões e 86 em Marcolândia, totalizando 205,1 MW de potência total instalada.

Ao considerar que o recorte espacial da pesquisa compreende o município de Marcolândia, este é constituído pelo Distrito Sede e suas localidades, dentre estas se sublinham as que possuem influência 
direta com a instalação dos aerogradores, a saber: Serra do Cícero Mundinho, Serra do Sebastião Silvestre e Cabeça da Ladeira.

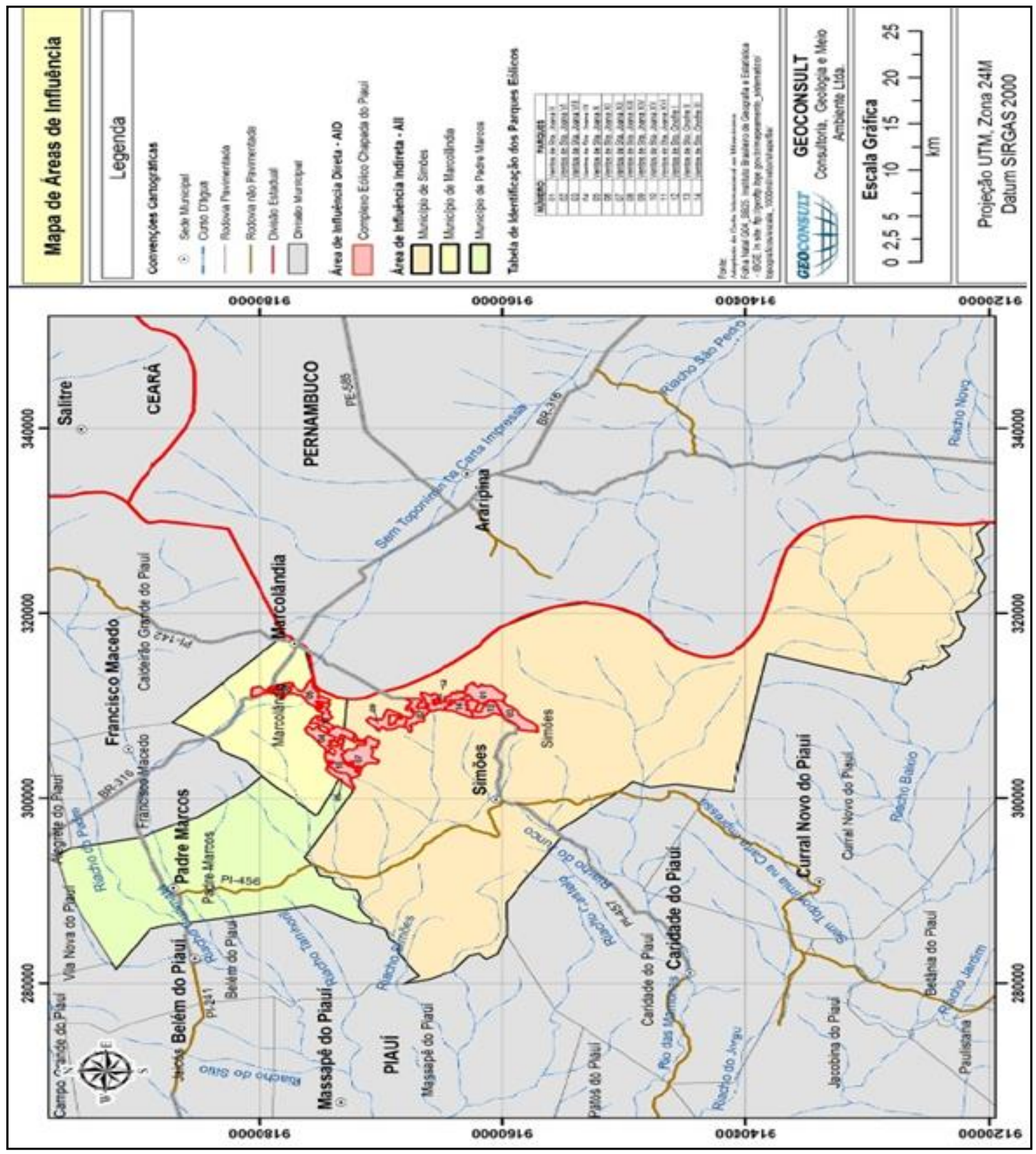

Figura04 - Complexo Eólico Chapada do Piauí I, estado do Piauí. Fonte: Piauí (2013).

A área delimitada para implantação dos parques eólicos abrange a porção piauiense da Bacia do Araripe (Chapada do Araripe), em que faz divisa com os estados de Pernambuco, Ceará e Piauí. 
Devido às condições geográficas do setor espacial em análise, os ventos típicos da região favorecem uma boa produção eólica, considerando sua incidência e constância durante o ano.

Ao analisar as vantagens locacionais da região, destacam-se alguns fatores que contribuíram para a implantação do referido projeto, com ênfase para: (i) situação geográfica ideal, em ambiente contemplado por correntes eólicas regulares e dotado de velocidades significativas, em áreas situadas em superfícies topograficamente plana e elevada da Chapada do Araripe; (ii) disponibilidade de terrenos, que oferecem grandes áreas livres, com pouca variação altimétrica e desprovidas de significativos condicionantes ambientais; (iii) existência de infraestrutura básica na região de entorno para dar suporte à implantação e operação do empreendimento; (iv) existência de levantamentos quanto ao potencial eólico da região. Diante deste cenário, Marcolândia-PI (Figura 05) ganha destaque.

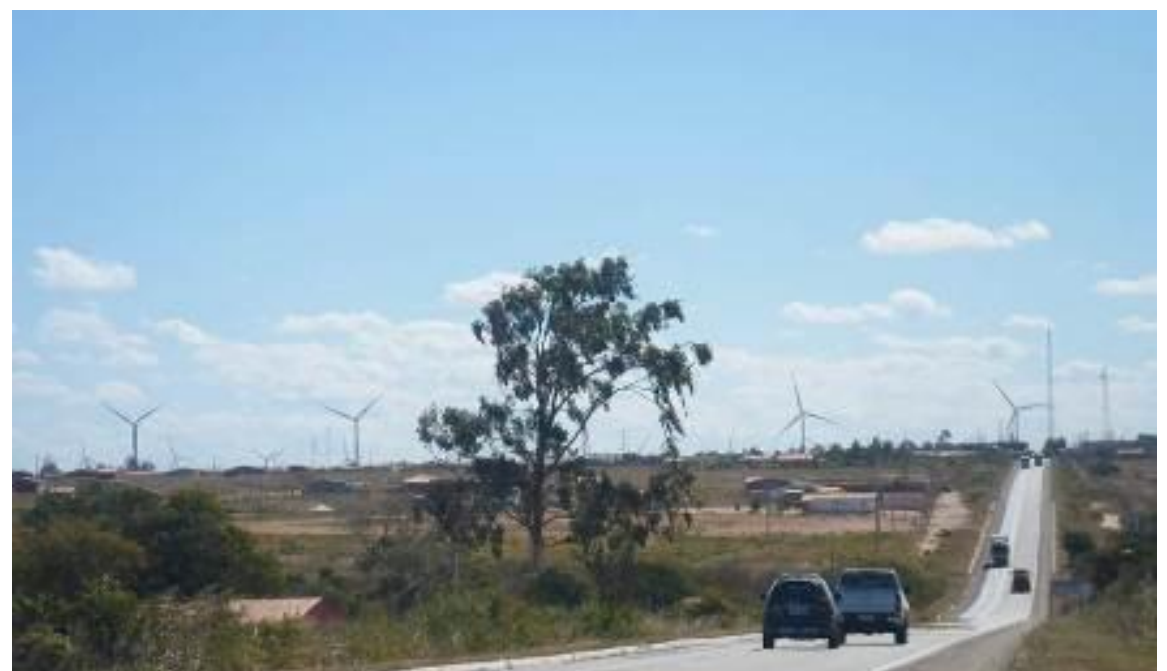

Figura 05 - Entrada do Município de Marcolândia, estado do Piauí. Fonte: Campêlo (2016).

Portanto, os fatores locacionais retratados, quando analisados de maneira integrada, refletem os impactos positivos que este vem causando no recorte espacial em epígrafe. Conforme dados colhidos na região (trabalho de campo), o proprietário, ao arrendar sua terra, assina um contrato, em que receberá por cada torre instalada em seu terreno o valor de $\mathrm{R} \$ 1.200,00$, durante o período de 20 anos, podendo este ser prorrogado por mais 20 anos. Atualmente são 92 contratos assinados em que são pagos cerca de R \$ 1.000.000,00 mensalmente pela empresa responsável aos proprietários.

$\mathrm{Na}$ perspectiva de contemplar a temática do trabalho, que é vislumbrar as energias renováveis como fontes sustentáveis, considerando o tripé ambiental, social e econômico, têm-se as particularidades que se materializam no ambiente. Neste sentido, além da geração de energia, os proprietários agregam valores às suas terras e ganham rendimentos extras por meio da atividade agrícola (com destaque para o cultivo da mandioca), bem como da pecuária, em associação com os aerogeradores (Figura 06). 


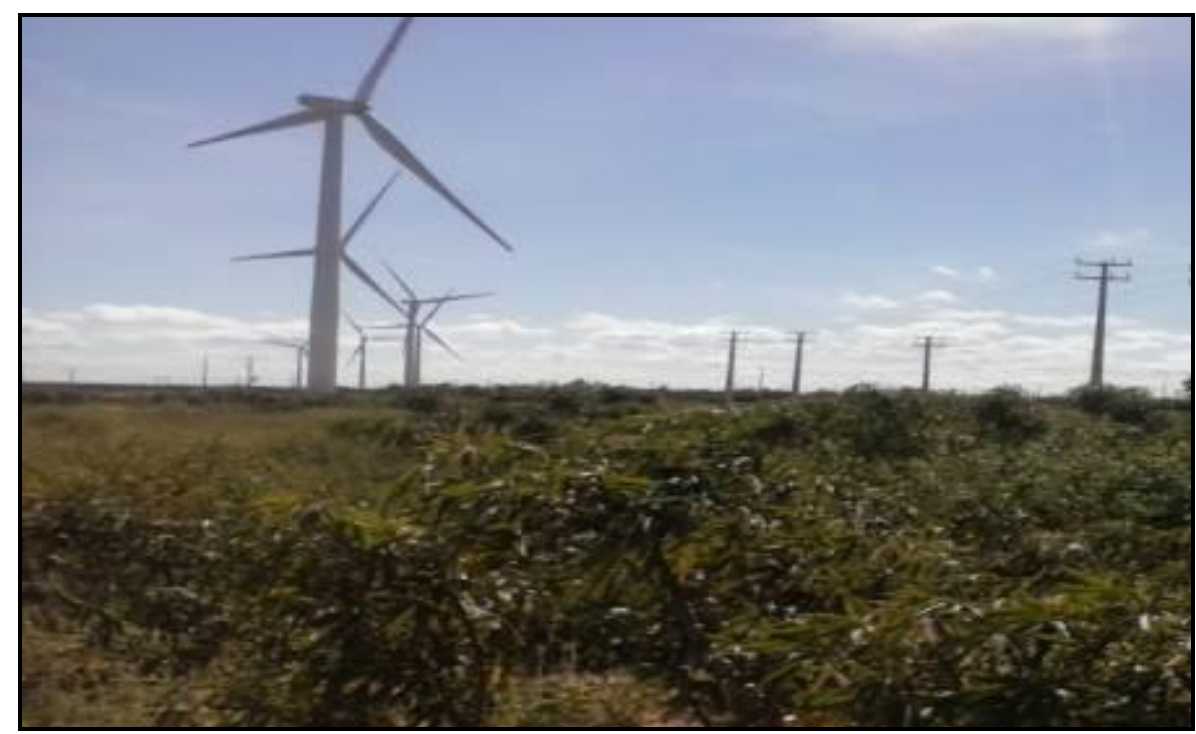

Figura 06 - Cultivo agrícola e geração de energia eólica em Marcolândia-PI. Fonte: Campêlo (2016).

Neste sentido, a atividade de geração de energia eólica nos moldes do desenvolvimento sustentável é a melhor maneira de agregar valores e obter rendimentos através da exploração racional e planejada das terras. Assim, o Complexo Eólico em destaque é de grande importância para a região, tendo em vista a inserção de Marcolândia-PI no cenário regional e nacional.

Deste modo, o pagamento pelo arrendamento da terra representa significativo retorno financeiro para os proprietários das áreas ocupadas. Assim, os impactos positivos referentes à geração de energia eólica são de grande magnitude e diz respeito à melhoria da qualidade de vida da população residente na região, que antes viviam somente da renda da agricultura, com a plantação de mandioca, feijão, milho, e de programas de transferência de renda do governo. Atualmente, a quantia que recebem mensalmente, por meio do arredamento de suas terras, contribui para o aumento do poder de compra da população.

Dessa forma, o município de Marcolândia-PI trilha o caminho do desenvolvimento sustentável, criando projetos, programas e ações, na perspectiva de conciliar a preservação do meio ambiente com o uso de tecnologias limpas e adequadas à produção de energia eólica,com resultados positivos quanto ao desenvolvimento da região e do Estado.

\section{CONSIDERAÇÕES FINAIS}

A energia elétrica é fundamental para garantir o desenvolvimento de uma determinada região. Porém, para assegurar a sustentabilidade das fontes energéticas é necessário que se busquem 
alternativas por meio de energias limpas, as chamadas fontes renováveis, que diante do cenário mundial de mudanças climáticas, ajuda a reduzir a emissão de gases causadores do efeito estufa.

Deste modo, o aproveitamento de energia eólica no mundo se consolida cada vez mais como uma matriz energética limpa e viável, sendo categorizada como uma fonte de produção de eletricidade promissora. Destaca-se que o Brasil é rico em recursos energéticos, com destaque para o grande potencial eólico. No Nordeste, o Piauí desponta na produção deste tipo de energia, apresentando expressivas potencialidades.

Diante do exposto neste trabalho e tomando por base os assuntos e teorias sobre o tema, constataram-se diversos benefícios advindos da geração de energia eólica para o município de Marcolândia-PI, na qual é gerada de forma sustentável, levando em conta os aspectos sociais, econômicos e ambientais.

Deste modo, pôde-se constatar um significativo retorno financeiro para a maioria dos proprietários das áreas ocupadas no Complexo Eólico, em que a população residente, que antes vivia da pequena agricultura e de programas governamentais, começou a obter melhorias no padrão de vida a partir dos arrendamentos de suas terras, tendo em vista os rendimentos recebidos.

\section{REFERÊNCIAS}

ABEEÓLICA. Associação Brasileira de Energia Eólica. Energia Eólica Mundial, 2015.

Disponívelem:<http://www.portalabeeolica.org.br/index. php/releases-menu.html?start =15>.Acesso em: 12 Out. 2015.

BRASIL. Instituto Brasileiro de Geografia e Estatística. Censo Demográfico 2010. IBGE, 2010.

DOWBOR, Ladislau. Alternativas energéticas no Brasil: alternativas inteligentes do uso de energia. In: ROVERE, Emilio Lébre; ROSA, Luiz Pinguelli; DOWBOR; Ladislau; SACHS Ignacy. Energias

Renováveis no Brasil: desafios e oportunidades. Santos, SP: Editora Brasileira de Arte e Cultura.

FADIGAS, Eliane A. F. A. Energia eólica (Série sustentabilidade). Barueri, SP: Manole, 2011.

GELLER, Howard S. Revolução Energética: políticas para um futuro sustentável. Rio de Janeiro:

RELUME DUMARÁ: USAid, 2003.

GOLDEMBERG, José. Energia e Desenvolvimento Sustentável (Série sustentabilidade). São Paulo:

Blucher, 2010.

LOPEZ, Ricardo Aldabó. Energia Eólica. 2. Ed. São Paulo: Artliber Editora, 2012.

OLIVEIRA, Glaube Roger. Patentes em Energia Eólica: uma forma sustentável de suprir as necessidades do Nordeste brasileiro. Rio de Janeiro: Editora Lumen Júris, 2013

PIAUÍ. Assembléia Legislativa do Piauí. Visita dos Parlamentares piauienses ao Complexo Eólico

Chapada do Piauí. 2015. 
SACHS Ignacy. Alternativas energéticas no Brasil: alternativas inteligentes do uso de energia. In: ROVERE, Emilio Lébre; ROSA, Luiz Pinguelli; DOWBOR; Ladislau; SACHS Ignacy. Energias Renováveis no Brasil: desafios e oportunidades. Santos, SP: Editora Brasileira de Arte e Cultura, 2011.

SIMAS, Moana; PACCA, Sérgio. Energia eólica, geração de empregos e desenvolvimento sustentável.

Estudos avançados, São Paulo, v. 27, n.77, p.100, 2013. Disponível em: <http://www.scielo.br/scielo. php?script=sci_arttext\&pid=S0103-40142013000100008>. Acesso em: 10 jun. 2016.

Recebido em: 14/08/2016

Aceito para publicação em: 01/10/2016 